\title{
The Links of Chain of Development of Physics from Past to the Present in a Chronological Order Starting from Thales of Miletus
}

\author{
Dr.(Prof.) V.C.A NAIR* \\ Educational Physicist, Research Guide for Physics at Shri J.J.T. University, Rajasthan-333001, India. \\ *nairvca39@gmail.com
}

\begin{abstract}
The Research Paper consists mainly of the birth dates of scientists and philosophers Before Christ (BC) and After Death (AD) starting from Thales of Miletus with a brief description of their work and contribution to the development of Physics. The author has taken up some 400 odd scientists and put them in a chronological order. Nobel laureates are considered separately in the same paper. Along with the names of researchers are included few of the scientific events of importance. The entire chain forms a cascade and a ready reference for the reader. The graph at the end shows the recession in the earlier centuries and its transition to renaissance after the $12^{\text {th }}$ century to the present.
\end{abstract}

Keywords: As the contents of the paper mainly consists of names of scientists, the key words are many and hence the same is not given

\section{INTRODUCTION}

As the material for the topic is not readily available, it is taken from various sources and the collection and compiling is a Herculean task running into some 20 pages. It is given in 3 parts, Part I, Part II and Part III. In Part I the years are given in Chronological order as per the year of birth of the scientist and accordingly the serial number. Part II consists mainly Nobel Laureates where the years do not follow the chronological order but the serial number follows the chronological order of awarding the Nobel Prize.

In Part III is a mention of total physicists in the world and the total number of Nobel laureates in Physics.

Each link of the chain consists of two parts. On the top is the year of birth of the scientist and at the bottom there is an arrow indicating the flow of time or the matter or information that follows .For example, a link for a confirmed year $585 \mathrm{BC}$ is shown as $\underset{585 \mathrm{BC}}{\rightarrow}$ In some cases the year shown is uncertain in which case the approximate sign [ ] is used. That is, a link for a doubtful year $520 \mathrm{BC}$ will be shown as $\sim 520 \mathrm{BC}$. This is a cut-short method and readyreckoner with the entire thing running like a cascade. The Nobel Prize winners are shown by an Asterisk $(*)$

\section{PART I}

\subsection{Era Before Christ (BC)}

1. Thales of Miletus : $\underset{\sim}{\sim} \mathrm{BC}$ The first Greek philosopher scientist who proposed that the world is made up of water and Earth is a disc floating on it. He also explained earthquakes without assigning them as work of Gods. $585 \mathrm{BC}$

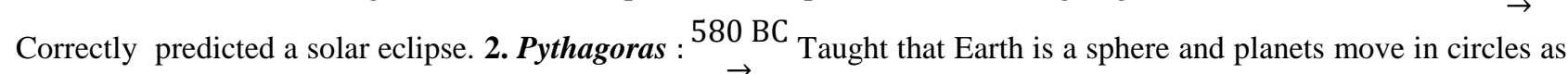
circle is very much related to right-angled triangle .3.Anaximander: $\stackrel{\sim}{\sim} \underset{\mathrm{BC}}{ }$ devised a cylindrical model of the Earth. 4. Leucippus: $\stackrel{500 \mathrm{BC}}{\rightarrow}$ credited with inventing the atomic theory. The word, 'Atom' came from the Greek word, 'Atomos'. 5. Empedocles: $\sim 494 \mathrm{BC}$ said that everything in the world is made up of four elements - Fire, Air, Water and Earth. 6. Democritu:s $\underset{40 \mathrm{BC}}{\rightarrow}$ developed the idea that everything is made of Atoms. 7. Plato: $\begin{gathered}427 \mathrm{BC} \\ \rightarrow\end{gathered}$ as a perfectionist argued that Earth is a perfect sphere and other bodies moved around it. 8. Heraklides of Pontus: $388 \mathrm{BC}$ argued that the Earth rotated on its axis every 24 hours. 9. Aristotle: $\stackrel{384 \mathrm{BC}}{\rightarrow}$ the first cosmologist came up with the idea 


\section{International Advanced Research Journal in Science, Engineering and Technology}

Vol. 5, Issue 10, October 2018

that the universe is series of concentric spheres centered on the Earth and rotating about it. He supported the idea of universe consisting of four elements, 'Fire', 'Air', 'Water' and 'Earth'. $348 \mathrm{BC}$ wrote the 'Republic' 10. Epicurus: $342 \mathrm{BC}$ Taught that the universe is made of innumerable and indestructible atoms which different from one another only in size, shape and position and moving in an infinite void. 11. Euclid: $\stackrel{300 \mathrm{BC}}{\rightarrow}$ presented his Geometry known as Euclidean Geometry. 12. Erasthenes of Cyrene: : $\underset{\rightarrow}{\sim} 273 \mathrm{BC}$ carried out the first reasonably accurate calculation of the size of the Earth. 13. Archimedes: $: \underset{\rightarrow}{265} \mathrm{BC}$ discovers density, specific gravity and the law of floatation and in $250 \mathrm{BC}$ established the basics of mechanics and hydrostatics. 14. Eratosthenes: $\sim 235 \mathrm{BC}$ correctly calculated the size of the Earth. 15. Hypparchus of Nicaea: $\stackrel{200 \mathrm{BC}}{\rightarrow}$ made the first thethe sunspots for the first time. 17. Lucretius $\sim 95 \mathrm{BC}$ deriving ideas from Epicurus discussed the motion of atoms in an infinite void.

\subsection{Era After Death (AD)}

18. Ptolemy: $\sim \underset{\mathrm{AD}}{\rightarrow}$ The Greek astronomer wrote the 13 volume 'Almagest' giving the description of the universe and known for a long time as the Ptolemic system. 19. Zhang Heng: $\stackrel{132 \mathrm{AD}}{\rightarrow}$ the Chinese scientist invents the first seismograph. 20. Scholars in Alexandria: $\begin{gathered}400 \mathrm{AD} \\ \rightarrow\end{gathered}$ The term, 'Chemistry' was used for the first time in Science. 21. Unknown Chinese Scholar: $\begin{gathered}635 \mathrm{AD} \\ \rightarrow\end{gathered}$ brings out a rule that the tail of a Comet always points away from the Sun. 22. The Arab Record: $840 \mathrm{AD}$ The first Arab record of observations of Sun Spots. 23. Arab Chemists: ${ }^{880} \rightarrow$ AD $\rightarrow$ The Arab chemists distill alcohol from urine 24. Alhazen: $\sim 965 \mathrm{AD}$ An Arabian physicist studied reflection and refraction of light. Explained the formation of rainbows. Studied the Sun during an eclipse using a camera, 'Obscura' 25. Science Library: $\begin{gathered}1005 \mathrm{AD} \\ \rightarrow\end{gathered}$ The first Science Library founded in Cairo, Egypt. 26. Chinese Astronomers: $\begin{gathered}1054 \mathrm{AD} \\ \rightarrow\end{gathered}$ witness the supernova explosion that created the Crab Nebula. 27. Large Comet: 1066 AD similar to Halley's Comet seen. 28. Magnetic Compass: $\stackrel{\sim}{1100 \mathrm{AD}}$ was used for the first time in China. 29. University of Paris: $\begin{gathered}\rightarrow 066 \mathrm{AD} \\ \rightarrow\end{gathered}$ founded.. 30. University of Cambridge: $\begin{gathered}1213 \mathrm{AD} \\ \rightarrow\end{gathered}$ started. 31. The Quill Pen: $\stackrel{\sim}{\rightarrow} 250 \mathrm{AD}$ invented. 32. Mechanical Clocks:

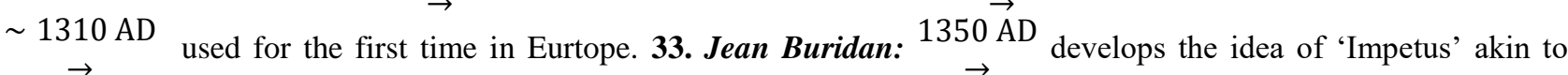

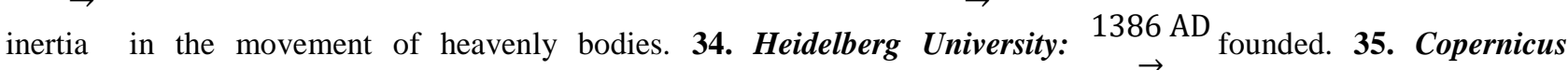
Nicolaus: $1473 \mathrm{AD}$ The Polish astronomer and doctor set out the idea that the Sun and not the Earth as the center of the Solar System. 36. Magellan Ferdinand: $\underset{\rightarrow}{\sim}$ The AD first European to describe the Magellanic Clouds in detail. 37. The + and - sign: $\stackrel{1489 \mathrm{AD}}{\rightarrow}$ First use of the + and - sign. 38. Leonard

Digges: $\stackrel{\sim 1500 \mathrm{AD}}{\rightarrow}$ invents the first reflecting telescope that magnifies the image primarily through a curved mirror. 36. Ferdinand Magellan: $\stackrel{1519 \mathrm{AD}}{\rightarrow}$ explains the Magellanic Clouds in detail. 39. Peter Apian: $\stackrel{1540 \mathrm{AD}}{\rightarrow}$ records the first European discovery of the fact that the tail of a Comet is always away from the $\overrightarrow{\text { Sun. 35. Copernicus }}$ Nicolaus: $\stackrel{1543 \mathrm{AD}}{\rightarrow}$ publishes a book on 'Revolutions of Heavenly Bodies'. 38. Leonard Digges: $\begin{gathered}1551 \mathrm{AD} \\ \rightarrow\end{gathered}$ Theodolite. 40. Horse-drawn Carriage: $\begin{gathered}1564 \mathrm{AD} \\ \rightarrow\end{gathered}$ introduced in England. 41. Galileo: $\begin{gathered}1564 \mathrm{AD} \\ \rightarrow\end{gathered}$ Made systematic observations of the heavens using Telescope. Proved that both light and heavy bodies fall with same speed in vacuum. Stressed on experimental verification of theories.. 42. Kepler Johannes: $\stackrel{1571 \text { AD }}{\rightarrow}$ Discovered the three laws of planetary motion. . 43. Tycho Brahe: $\begin{gathered}1572 \mathrm{AD} \\ \rightarrow\end{gathered}$ observed 'Supernova'. 44. Thomas Digges 1576 AD $\rightarrow$ suggests that stars are distributed into an endless infinity of space. . 41. Galileo: ${ }_{\rightarrow}^{1581 \mathrm{AD}}$ Sudies the behavior of pendulums. 45. 


\title{
International Advanced Research Journal in Science, Engineering and Technology
}

\author{
Vol. 5, Issue 10, October 2018
}

Gassendi Pierre $\stackrel{1592 \mathrm{AD}}{\rightarrow}$ Asserted that motion is relative. Also espoused the atomic theory. He said that light is a stream of particles. He gave Aurora borealis its name. 43. Tycho Brahe: $1596 \mathrm{AD}$ Made accurate measurements of the positions of stars and the movements of the planets. 46. Rene Descartes: $\stackrel{1596}{A D}$ Invented the system of Co-ordinate Geometry known as the Cartesian Geometry. 42. Kepler Johannes: $\stackrel{1604 \mathrm{AD}}{\rightarrow}$ Observed Supernova. 41. Galileo: $\underset{1609 \mathrm{AD}}{\rightarrow}$ First person to use a refracting telescope for astronomical observations. . 41. Galileo: ${ }^{1610 \mathrm{AD}} \mathrm{Book}_{\text {on }}$ 'Starry Messenger' published. 47. Robert Boyle: $\underset{\rightarrow}{1627 \mathrm{AD}}$ Enunciates Boyle's Law. 48. Huygens Christiaan: $\underset{\rightarrow}{1629}$ AD Invented pendulum clocks. Proposed wave theory of light. Discovered Titan and recognized the nature of Saturn's rings. 49. Pierre Gassendi: $\stackrel{1631 \mathrm{AD}}{\rightarrow}$ First person to observe the transit of planet Mercury across the face of the Sun. 50. Harvard College: $\stackrel{1636 \mathrm{AD}}{\rightarrow}$ was founded. 51. Galileo's Son: $\stackrel{1641 \mathrm{AD}}{\rightarrow}$ Built first pendulum clock. 52. Sir Isaac Newton: $\begin{gathered}1642 \mathrm{AD} \\ \rightarrow\end{gathered}$ Discovered the law of gravity and the laws of motion that bears his name. Developed

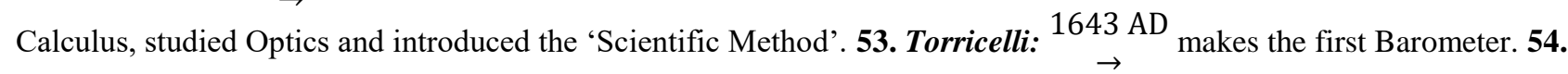
Romer: $\stackrel{1644 \mathrm{AD}}{\rightarrow}$ Measured the speed of light. 55. Johannes Hevelius: $\stackrel{1647 \mathrm{AD}}{\rightarrow} \overrightarrow{\text { Made }}$ the first map of the Moon. 56. Halley Edmond: 1656 AD A comet named after him is found to be in regular orbit around the Sun. Correctly estimated the distance of the Sun from the Earth. 57. John Gregory: $\underset{\rightarrow}{1663}$ AD Prepared a reflecting telescope called Gregorian Telescope. 58. Robert Hooke: $\begin{array}{r}1664 \mathrm{AD} \\ \rightarrow\end{array}$ Discovers the great red spot of Jupiter. . 52. Sir Isaac Newton: $1665 \mathrm{AD}$ Due to the outbreak of Plague, university of Cambridge is closed and hence Newton back to his home at Woolsthorpe where he made further discoveries. 59. French Royal Academy of Sciences: $1666 \mathrm{AD}$ got established. 60. Cassegrain: $\underset{\rightarrow}{1672}$ AD Designs a Telescope called Cassegrain Telescope. 61. Charles II $\begin{aligned} & \overrightarrow{6675} \mathrm{AD} \\ & \rightarrow\end{aligned}$ Founds the Royal Greenwich Observatory. 62. Berkeley (Bishop) George: $\begin{gathered}1685 \mathrm{AD} \\ \rightarrow\end{gathered}$ Argued that all motion is relative and must be measured against

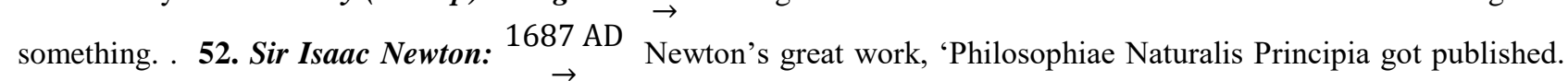
48. Huyge of Least Action'ns Christiaan: $\stackrel{1690 \mathrm{AD}}{\rightarrow}$ publishes his 'Treatise on Light'.63. Bradley James: $1693 \mathrm{AD}$ Using aberration measured the speed of light to be $308300 \mathrm{~km} / \mathrm{sec}$. 64. de Maupertuis, Pierre Louis Moreau $\underset{\rightarrow}{1698 \mathrm{AD}}$ The first person to formulate the 'Principle of Least Action'. 65. Steam-powered Pump: $\begin{gathered}\text { 1698AD } \\ \rightarrow\end{gathered}$ Patented. 66. Immanuel Kant: $\stackrel{1700 \mathrm{AD}}{\rightarrow}$ suggests that the distant nebulae might be complete star systems beyond the Milky Way. 52. Sir Isaac Newton: $\begin{aligned} & 1704 \mathrm{AD} \\ & \rightarrow\end{aligned}$ publishes his 'Opticks' wherein he considers light as a stream of particles called 'corpuscles'. 67. Leonhard Euler: $\stackrel{1707 \mathrm{AD}}{\rightarrow}$ Developed the idea of 'Principle of Least Action' and 'Calculus of Variations' which paved the way for the work of Joseph Lagrange and later on for the development of Quantum Mechanics. He also used the mathematical notations such as 'e', ' $\pi$ ' and ' 1 ' which have become standard. 66. Newcomen: $\underset{\rightarrow}{1712 \mathrm{AD}}$ develops an improved Steam Engine. 67. Gabriel Fahrenheit: $\stackrel{1714 \mathrm{AD}}{\rightarrow}$ made a mercury-inglass thermometer named after him. 68. Michell John: $\stackrel{1724 \text { AD }}{\rightarrow}$ First person to come up with the idea of 'Black Holes' 69. Cavendish Henry: $\stackrel{1731 \mathrm{AD}}{\rightarrow}$ Devised a torsion balance to measure the mean density of the Earth. Accurately measured Newton's constant of gravitation. He said that air is a mixture of gases and can be weighed. 70. Coulomb Charles Agustin de: $\stackrel{1736 \mathrm{AD}}{\rightarrow}$ French physicist who discovered Coulomb's law regarding the force between charges. 71. Lagrange Josreph Louis: $\stackrel{1736 \mathrm{AD}}{\rightarrow}$ Developed techniques that proved invaluable in the formulation of the Group Theory and the Lagrangian Function in the explanation of planets and also sub-atomic particles. 72. Anders Celsius: $\underset{\substack{1742 \mathrm{AD} \\ \rightarrow} \text { Invents a thermometer named after him. 73. Lavoisier Antoine Laurent: }}{1743 \mathrm{AD}}$ Disproved Phlogiston 


\title{
International Advanced Research Journal in Science, Engineering and Technology
}

\author{
Vol. 5, Issue 10, October 2018
}

theory 74. Princeton University: $\begin{aligned} & 1746 \mathrm{AD} \\ & \rightarrow\end{aligned}$ Founding of Princeton University. 75. Laplace Pierre Simon: $\begin{gathered}1749 \mathrm{AD} \\ \rightarrow\end{gathered}$ Updated Kepler's laws of planetary motion. Introduced Laplace's equation and the Laplacian operator in mathematical Physics. 76. Benjamin Franklin: $\begin{aligned} & 1749 \mathrm{AD} \\ & \rightarrow\end{aligned}$ invents the Lightening Rod. $\begin{gathered}1752 \mathrm{AD} \\ \rightarrow\end{gathered}$ and carries out the famous Kite Experiment. 77. Rumford Count (Benjamin Thompson) $1753 \mathrm{AD}$ Asserted that Heat is a form of energy and not a substance called 'caloric'. 78. Moscow University: $\underset{\rightarrow}{1755 \mathrm{AD}} \vec{\rightarrow}$ Founding of Moscow University. 79. Olbers, Heinrich Wilhelm Mattaus $1758 \mathrm{AD}$ Improved method of calculating the orbits of planets. Also discovered two of the minor planets. 80. Daniel Bernoulli $\stackrel{1760 \mathrm{AD}}{\rightarrow}$ Discovers that electricity obeys an inverse square law similar to law of gravity. 81. James Watt: $\begin{gathered}1765 \mathrm{AD} \\ \rightarrow\end{gathered}$ Develops an improved steam engine.82. Dalton John: $\begin{gathered}1766 \mathrm{AD} \\ \rightarrow\end{gathered}$ Brings out his famous atomic theory saying that different elements can be distinguished by their difference in their weights. 83. Wollaston William: $1766 \mathrm{AD}$ Both a physicist and a physician observed dark lines in the solar spectrum. Discovered elements Rhodium and Palladium. 84. Encyclopedia Britannica: $1768 \mathrm{AD}$ Weekly preparation started. 85. Oxygen: $1771 \mathrm{AD}$ Element Oxygen discovered. 86. Brown Robert: ${ }_{1773} \mathrm{AD}$ Famous for the Brownian Motion of pollen grains. 87. Young Thomas: $\begin{gathered}1773 \mathrm{AD} \\ \rightarrow\end{gathered}$ Established the wave theory of light. Studied Elasticity of materials. 88. Nevil Maskelyne: $\underset{\rightarrow}{1774 \mathrm{AD}}$ Determines the mass of the Earth by the deflection of a plumb line near a mountain. 89. Malus Etienne Louis: $\underset{\rightarrow}{1775 \mathrm{AD}}$ Discovers the polarization of light. 90. Avogadro Amedeo: $\stackrel{1776 \mathrm{AD}}{\rightarrow}$ Famous for the Avogadro's law and the number bearing his name. 91. Gauss Karl Friedrch: $1777 \mathrm{AD}$ German mathematician and astronomer developed non-Euclidean geometry useful in the explanation of General Theory of Relativity. 92. Hans Christian Oersted: $\begin{gathered}1777 \mathrm{AD} \\ \rightarrow\end{gathered}$ Discovered magnetic effect of electric current. 92. Fraunhofer Joseph John: $1787 \mathrm{AD}$ Found some 574 lines in the solar spectrum and the lines named after him. 93. Fresnel Augustin Jean: ${ }^{1788 \text { AD }}$ Firmly established the wave theory of light and asserted that light waves are transverse waves and not longitudinal waves. 94. Gay-Lussac, Joseph Louis: $1788 \mathrm{AD}$ Studied the behavior of gases and famous for the law named after him. 95. Definition of Metre: $\stackrel{1790 \mathrm{AD}}{\rightarrow}$ Metre is defined in the National Assembly in the revolutionary France as 1 ten-millionth of the distance from the north pole to the equator. 96. Faraday Michael: $1791 \mathrm{AD}$ Both a physicist and chemist. Extensively studied Electricity and Magnetism. Introduced the idea of Fields and lines of force. 97. Herschel: $\underset{\rightarrow}{1800 \mathrm{AD}}$ Discovers infrared radiation. 98. Richard Trevithick $1800 \mathrm{AD}$ Builds a high pressure steam engine. 99. Doppler Christian Johann: $\begin{gathered}1803 \text { AD } \\ \rightarrow\end{gathered}$ Known for the famous Doppler Effect. .82. Dalton John: $\begin{gathered}1803 \text { AD } \\ \rightarrow\end{gathered}$ Publishes the first table of Atomic Weights. 100. Jacobi Carl Gustav Jacob: ${ }^{1804}$ AD Studied symmetry and Invariance in Physics. The Jacobian determinant with ideas of Hamilton proved to be $\overrightarrow{\text { useful in }}$ Quantum Mechanics. 101. Weber Wilhelm Eduard: $1804 \mathrm{AD}$ Studied the electrostatic and electromagnetic behavior of materials, the ratio of which is found to be Weber's constant equal to the velocity of light. 102.Hamilton William Rowan: $\begin{array}{r}1805 \text { AD } \\ \rightarrow\end{array}$ child prodigy discovered the 'Principle of Least Action' in the context of light paths. The Hamiltonian interpretation of the equations of motion of Joseph Lagrange is very famous and used in Wave Mechanics. Developed the 'Quarternion theory which is the Algebra of four dimensions. He devised the term, 'Vector' in its modern mathematical context. 87. Young Thomas: $1807 \mathrm{AD}$ Introduces the concept and the word, 'Energy'. 103. Use of Gas Lights: ${ }^{1807 \mathrm{AD}}$ First use of gas lights in the London streets. 104. Robert Fulton: $\stackrel{1807 \mathrm{AD}}{\rightarrow}$ Improved steam boat tested in the East River off New York. 89. Malus Etienne Louis: $\begin{gathered}1807 \& 1808 \text { AD } \\ \rightarrow\end{gathered}$ Concept of 'Double Refraction' in Polarization of light. 105. Humphrey Davy: $\begin{aligned} & \rightarrow \rightarrow \\ & \rightarrow\end{aligned}$ Invents the electric arc light. 106. Richard Trevthick: $\stackrel{1808 \mathrm{AD}}{\rightarrow}$ builds the first passenger railway in London. 107. University of Berlin: $\begin{gathered}1810 \mathrm{AD} \\ \rightarrow\end{gathered}$ was founded. 108. Bunsen Robert: $\stackrel{\text { 1811 AD }}{\rightarrow}$ Along with Gustav 


\section{International Advanced Research Journal in Science, Engineering and Technology}

Vol. 5, Issue 10, October 2018

Kirchhoff established basic principles of Spectroscopy. Invents a burner named after him as the 'Bunsen Burner'. . 92. Hans Christian Oersted: $1812 \mathrm{AD}$ Confirmed that an electric current produces a magnetic field. 109. George Stephenson: $\begin{aligned} 1814 \mathrm{AD} \\ \rightarrow\end{aligned}$ First locomotive starts working. 110. Angstrom Anders Jonas: $\stackrel{1814 \mathrm{AD}}{\rightarrow}$ Swedish pioneer of spectroscopy whose name is associated with the wavelength of light known as 'Angstrom Unit'. 111. Foucault (Jean Bernard) Leon: $1814 \mathrm{AD}$ Invented the Gyroscope and made a pendulum to demonstrate the rotation of Earth. 105.

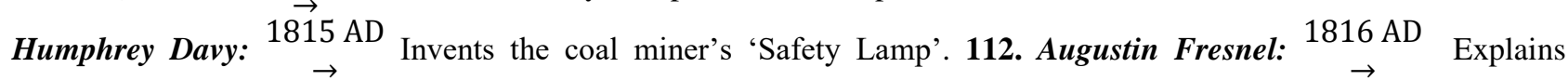
Diffraction based on his wave theory of light. 113. Strethoscope: $1816 \mathrm{AD}$ was invented. 114. Tyndall John: $\stackrel{1820 \mathrm{AD}}{\rightarrow}$ The Tyndall ecolor of the skyffect helps to explain the blue .

115. Loschmidt, Johann Joseph: ${ }^{1821} \mathrm{AD}$ Successfully measures the size of molecules in the air with reasonable accuracy.116. Kelvin Lord: ${ }^{1824} \overrightarrow{\mathrm{AD}}$ Lot of contribution to thermodynamics and electrodynamics. Laid the transatlantic cable. Contributed to Astronomy in finding the age of the Earth. Devised a scale of temperature known as the Kelvin scale of temperature. 117. Kirchhoff Gustav Robert: $\stackrel{1824 \mathrm{AD}}{\rightarrow}$ Famous for the Kirchhoff's law of thermal radiation. Took part in Quantum theory of thermal radiation. 118. Balmer Johann Jakob: 1825 AD Studied Spectroscopy. Famous for Balmer series of Hydrogen spectrum. 119. Passenger Steam Train: $\overrightarrow{1825 \text { AD }} \rightarrow$ First passenger steam train started. 120. Cannizzaro Stanislao: ${ }_{\rightarrow}^{1826} \mathrm{AD}$ First person to point out the difference between atomic weight and molecular weight. He was the first to make a table of atomic and molecular weights based on theatomic weight of hydrogen as the fundamental unit of mass. This helped in the preparation of the Periodic Table.

121. Heinrich Olbers: $\stackrel{1826 \mathrm{AD}}{\rightarrow}$ Says that the light from distant stars is absorbed in a thin gruel of material between the stars. 122. Riemann,(GeorgFriedrich) Benhard: $\stackrel{1826 \mathrm{AD}}{\rightarrow}$ Developed non-Euclidean geometry which later on helped in Einstein's General Theory of Relativity. 86. Brown Robert: ${ }^{1827}$ AD Experimental observation of Brownian motion. 102.Hamilton William Rowan: $1827 \mathrm{AD}$ Modifies equation of motion derived by Lagrange and makes it simpler. 123. Meyer (Julius) Lothar: $\underset{1830 \mathrm{AD}}{\rightarrow}$ Prepared periodic pattern of elements independently of Dmitri

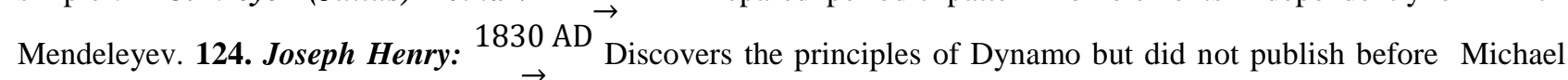
Faraday. 125. James Clerk Maxwell: $\overrightarrow{1831}$ AD Discovers the famous electromagnetic equations. Does research on color vision. 126. Michael Faraday: $\underset{1831 \overrightarrow{A D}}{\rightarrow}$ Discovers electromagnetic induction. 127. Benolt Clapeyron: $\begin{aligned} & 1831 \mathrm{AD} \\ & \rightarrow\end{aligned}$ Develops the second law of thermodynamics.. 128. Crookes William: $\stackrel{1832 \mathrm{AD}}{\rightarrow}$ Both a British physicist and chemist experiments of discharge of electricity through gases. 129. Karl Gauss: $\stackrel{1833}{A D}$ Along with William Weber develops an electric telegraph. 130. Mendeleyev Dmitri: $\underset{\rightarrow}{1834 \mathrm{AD}}$ Brings out an acceptable Periodic Table. Also discovers new elements. 131. Stefan Josef: $\stackrel{1835 \mathrm{AD}}{\rightarrow}$ Along with Boltzmann discovers the law of thermal radiation. 132. Lockyer, (Joseph) Norman: $\stackrel{1836 \mathrm{AD}}{\rightarrow}$ Discovers Helium Gas.. 133. Van der Waals, Johannes Diderik: $\begin{aligned} & \text { 1837 AD } \\ & \rightarrow\end{aligned}$ famous equation of state for gases. 134. Mach Ernst: $\stackrel{1838 \mathrm{AD}}{\rightarrow}$ The Mach number which gives the relative speed of an object with that of sound. 135. Morley Edward Williams: $\underset{1838 \mathrm{AD}}{\rightarrow}$ Carried out experiment with Albert Michelson to detect 'ether'. 136. Charles Goodyear: $\stackrel{1839 \mathrm{AD}}{\rightarrow}$ Develops vulcanization of rubber. 137. Rayleigh, Lord*: $\stackrel{1842 \mathrm{AD}}{\rightarrow}$ Nobel Laureate of 1904 for the discovery of Argon. Research on Sound and black body radiation. 138. Doppler Christian: $\stackrel{1842 \mathrm{AD}}{\rightarrow}$ Change in frequency of sound or light due to the motion of an object known as Doppler effect. 139. Julius Meyer: $\stackrel{1842 \mathrm{AD}}{\rightarrow}$ First person to state the law of conservation of energy. 140. Boltzmann Ludwig: $\stackrel{1844 \mathrm{AD}}{\rightarrow}$ 


\section{International Advanced Research Journal in Science, Engineering and Technology}

Vol. 5, Issue 10, October 2018

Research in Thermodynamics and Statistical mechanics. Famous for the Boltzmann constant. 141. Rontgen Wilhelm Conrad*: $^{1845 \mathrm{AD}}$ Winner of the 1901 Nobel Prize for the discovery of X-rays.

142. Earl of Rosse: $1845 \mathrm{AD}$ Built a most powerful 72 -inch reflecting telescope in Birr Castle in central Ireland. 143.

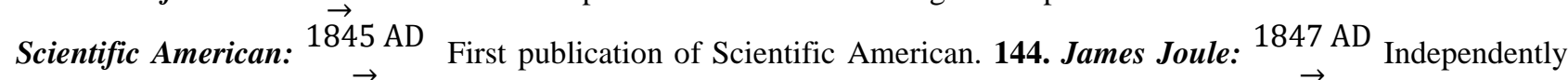
discovers the law of conservation of energy. 145. Fizeau: $\stackrel{1849}{\rightarrow} \mathrm{AD}$ Measures the correct value for the speed of light. 116. Kelvin Lord: $\begin{array}{r}1849 \mathrm{AD} \\ \rightarrow\end{array}$ Coins the term, 'Thermodynamics'. 111. Foucault (Jean Bernard) Leon: $1850 \mathrm{AD}$ Found that the speed of light in air is larger than that in water.146. Fitzgerald, George Francis: 1851 AD $\rightarrow \rightarrow$ objects get shortened as per theory of Relativity known as the Fitzgerald contraction. 116. Kelvin Lord: $1851 \mathrm{AD}$ Develops the concept of Absolute Zero. 147. Becquerel (Antoine) Henri*: 1852 AD The 1903 Nobel Laureate for the

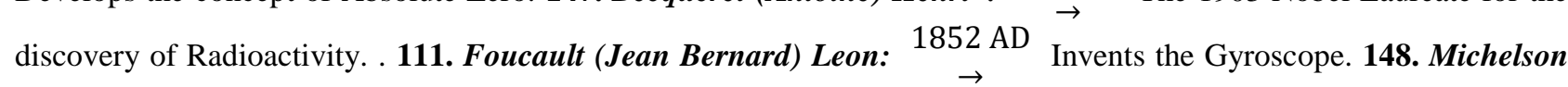
Albert Abraham*: $\stackrel{1852 \mathrm{AD}}{\rightarrow}$ The 1907 Nobel Laureate. Famous for his experiments with Morley for the detection of ether. 149. Poynting, John Henry: $1852 \mathrm{AD}$ Determined the density of the Earth and the Gravitational constant. Worked on electromagnetism and found that the flow of electromagnetic energy across a surface can be expressed in the form of a vector called Poynting vector.150.Lorentz, Hendrik Antoon*: $\begin{gathered}1853 \text { AD } \\ \rightarrow\end{gathered}$ The 1902 Nobel Laureate. Research on electromagnetism, coined the term, 'electron'. Worked on relativity and developed the transformation equations. 151. Onnes, Heike Kamerligh $*$ : $\rightarrow$ AD The Nobel Laureate of 1913. Investigations on the properties of matter at very low temperatures which led, inter alia, to the production of liquid helium.

152. Hermann Von Helmholtz: $\begin{gathered}1854 \mathrm{AD} \\ \rightarrow\end{gathered}$ Suggests that the Sun is kept hot due to gravitational energy released as it shrinks due to its own weight. 153. Max Planck $* \underset{\rightarrow}{1858 \mathrm{AD}}$ The 1918 Nobel Laureate for the discovery of the law of black body radiation and energy quanta. 154. Atlantic Telegraph Cable: $\begin{gathered}1858 \mathrm{AD} \\ \rightarrow\end{gathered}$ Laid the first Atlantic telegraph cable. 155. Arrhenius Svante August 1859 AD First person to explain when a chemical compound dissolves in water, it dissociates into electrically charged ions.

156 .Jean Lenoir: $1860 \mathrm{AD}$ First vehicle driven by internal combustion engine developed. 157. Bragg Sir William Henry*: $1862 \mathrm{AD}$ Winner of the 1915 Nobel Prize for the study of crystal structure using X-rays. 158. Friedrich Bessel: $\underset{\rightarrow}{1862 \overrightarrow{\mathrm{AD}}}$ Discovered the first white dwarf known as Sirius B 159. Richard Gatling: ${ }^{1862 \mathrm{AD}} \rightarrow$ Invents the machine gun. 160. Lenard Phillip Eduard $1862 \mathrm{AD}$ The 1905 Nobel laureate for his work on cathode rays and

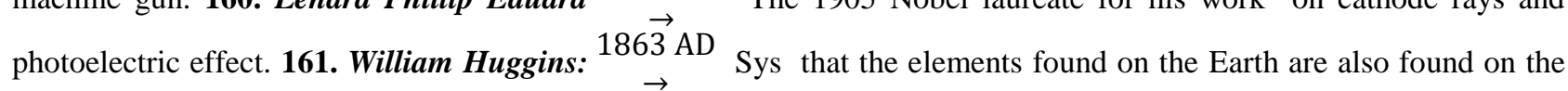
stars. 162. The National Academy of Sciences: $\underset{1863 \mathrm{AD}}{\rightarrow}$ Founded in USA. 163. Minkowski Hermann: $\begin{gathered}1864 \mathrm{AD} \\ \rightarrow\end{gathered}$ of Einstein's teachers according to whom physical events take place in four-dimensional space-time. . 125. James Clerk Maxwell: $1864 \mathrm{AD}$ Brings out his famous electromagnetic equations and also predicts the existence of radio waves. 164. Wien Wilhelm $*: \begin{gathered}1864 \mathrm{AD} \\ \rightarrow\end{gathered}$ Winner of the 1911 Nobel prize for his theories on thermal the study of effect of magnetic field on light. 166. Lebedev, Pyotr Nikolayevich: $\stackrel{1866 \mathrm{AD}}{\rightarrow}$ First person to measure pressure of light. 167. Millikan Robert Andrews*: 1868 AD Winner of the 1923 Nobel Prize. Measurement of charge of electron. Also did research on Photoelectric effect and Cosmic Rays. 168. Lockyer and Janssen: $\begin{gathered}\rightarrow 868 \mathrm{AD} \\ \rightarrow\end{gathered}$ Independently of one another discover helium in the Sun. 169. Sommerfeld Arnold $\underset{\rightarrow}{1868 \mathrm{AD}}$ Great atomic physicist famous for the elliptical orbits. 170. Wilson Charles Thomson Rees*: 1869 AD Winner of the 1927 Nobel prize. Developed a cloud chamber named 


\title{
International Advanced Research Journal in Science, Engineering and Technology
}

\author{
Vol. 5, Issue 10, October 2018
}

after him. 171. Journal, Nature: $\underset{\rightarrow}{1869}$ AD Journal published for the first time. 172. Perrin, Jean Baptiste $*: \begin{aligned} & 1870 \mathrm{AD} \\ & \rightarrow\end{aligned}$ The winner of the Nobel prize in $1926 \overrightarrow{6}$ for his work on discontinuous structure of matter and specially for the discovery of sedimentation equilibrium. 173. William Crookes $1870 \mathrm{AD}$ Study of discharge of electricity through gases. 174. Cavendish Laboratory: $\stackrel{1871 \mathrm{AD}}{\rightarrow}$ The Cavendish Laboratory is established in England. 175. Rutherford Earnest*: 1871 AD
$\rightarrow$ Winner of the 1908 Nobel prize for Chemistry. Discovery of the Atomic nucleus and three types of nuclear radiations such as Alpha, Beta and Gamma rays. Invented the process of radioactive dating. 176. De Sitter Willem: $1872 \mathrm{AD}$ Helped Einstein to develop a mathematical model in General Theory of Relativity. 177. Shwarzschild Karl: $\underset{1873}{\rightarrow}$ AD Solutions for equations of General Theory of Relativity which later on led to the discovery of black holes. 178. Lyman Theodore: $\stackrel{1874 \mathrm{AD}}{\rightarrow}$ Famous for the Lyman series of the hydrogen spectrum. 179. Stark, Johannes $1874 \mathrm{AD}$ Famous for the Stark effect which is the splitting of spectral lines in an electric field. 180 Lewis Gilbert Newton: $1875 \mathrm{AD}$ Invention of the covalent bond in which the atoms are arranged by sharing of electrons. . 173. William Crookes $1875 \mathrm{AD}$ Invents radiometer named after him. 181. Aston, Francis William: $\begin{aligned} & \text { 1877 AD } \\ & \rightarrow\end{aligned}$ techniques of mass spectroscopy and did research on isotopes. 182. Asaph Hall: $\begin{gathered}\text { 1877 AD } \\ \text { Found the two Moons of }\end{gathered}$ Mars. 183. Jeans, James Hapwood: 1877 AD Developed kinetic theory of gases. Author of 'Heat Death. 183. Soddy Federik $1877 \mathrm{AD}$ Winner of 1921 Nobel prize for Chemistry. Worked on isotopes and radioactive decay.184. Meitner Lise: $\underset{\rightarrow}{1878 \overrightarrow{\mathrm{AD}}}$ Research on Nuclear Fission. 185. Einstein Albert*: $1879 \mathrm{AD}$ Winner of the 1921 Nobel prize for the photoelectric effect. Propounder of both the special theory and Research on black body radiation. Famous for the Stefan-Boltzmann Law. 187. Thomas Edison: $\stackrel{1879}{\rightarrow} \mathrm{AD}$ Making of the electric light bulb. 188. Laue, Max Theodor Felix von*: $1879 \mathrm{AD}$ Winner of the 1914 Nobel prize for the diffraction of X-rays by crystals. 189. Richardson Owen Williams $\begin{gathered}1879 \overrightarrow{\mathrm{AD}} \\ \rightarrow\end{gathered}$ Winner of the 1928 Nobel prize. Research on thermionic emission and development of vacuum tubes. 190. Bishop Berkeley: $1880 \mathrm{AD}$ The bulging of the Earth at the equator is not due to centrifugal force but due to relative motion. 191. Davisson Clinton Joseph*: $1881 \mathrm{AD}$ Winner of the 1937 Nobel prize for the experimental finding of the wave nature of electrons. 192. Electrical generation and distribution: $\stackrel{1881 \mathrm{AD}}{\rightarrow}$ First practical electrical generation and distribution system developed. 193. Born Max : $1882 \mathrm{AD}$ The 1954 winner of Nobel prize. Famous for the statistical interpretation of the wave function. 194. Eddington Sir Arthur: $\begin{array}{r}1882 \text { AD } \\ \rightarrow\end{array}$ astrophysicist. Confirmed Einstein's General theory of Relativity during 1919 solar eclipse.195. Geiger, Hans William: 1882 AD Developed a counter for measuring Radioactivity.196. Noether(Amalle) Emmy: 1882 AD Made important contributions to the development of the concepts of symmetry and non-commutative fields.197. Hess Victor Francis $*$ : 1883 AD The 1936 winner of the Nobel prize for his research on Cosmic rays. 198. Gottleb Daimler: 1883 AD $\rightarrow$ the first modern internal combustion engine. 199. Debye, Peter Joseph Willem $*$. 1884 AD Winner of the 1936 Nobel Prize for Chemistry. Research on structure of molecules, specific heats and X-ray diffraction. 200. Bohr, Niels Hendrik David*: $\begin{gathered}1885 \mathrm{AD} \\ \rightarrow\end{gathered}$ Winner of the 1922 Nobel prize for his research on the structure of atom. 201.Automobile and motor bike: $\stackrel{1885 A}{\rightarrow} \mathrm{AD}_{\text {Invented. 202. Siegbahn, (Karl) Manne Georg*: }} \begin{gathered}\text { 1886 } \mathrm{AD} \\ \rightarrow\end{gathered}$ Winner of the

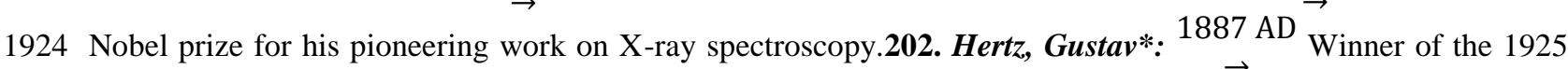
Nobel prize for his work on separation of isotopes. 203. Moseley, Henry Gwyn Jeffreys: $\stackrel{1887 \text { AD }}{\rightarrow}$ A pioneer of X-ray spectroscopy. Took part in the formation of the periodic table. 204. Nikola Tesla: $1887 \mathrm{AD}$ An alternating current motor invented. 205. Michelson-Morley Experiment: $\stackrel{1887 \mathrm{AD}}{\rightarrow}$ Experiment carried out the famous experiment for the 


\title{
International Advanced Research Journal in Science, Engineering and Technology
}

\author{
Vol. 5, Issue 10, October 2018
}

detection of motion of Earth through ether, but failed to detect. 206.Schrodinger, Erwin*: ${ }^{1887}$ AD Developed the wave mechanics formulation of the Quantum Theory. 207. Friedmann Aleksandr Aleksandrovich: ${ }^{1888}$ AD $\rightarrow$ Worked on hydromechanics and meteorology. Found solutions for Einstein's equations of General Theory of Relativity. 208. Heinrich Hertz: 1888 AD

Production of long-wavelength radiation. 209. Raman Chandrasekhara Venkata*: 1888 AD Winner of the 1930 Nobel Prize for the effect named after him. 210. Stern Otto*: 1888 AD Winner of the 1943 Nobel Prize. Revealed existence of electron spin and determined the magnetic moment of proton. 211. Hubble Edwin Powell: ${ }^{1889}$ AD Says that what is nebulae are actually galaxies. Gave the theory of expansion of the universe. 212. Eiffel Tower: 1889 AD Work completed. 213. Bragg (William) Lawrence*: 1890 AD Winner of the 1915 Nobel Prize for the study of crystal structure using X-rays. 214. Edward Pickering: $1890 \mathrm{AD}$ Measurement of temperature of stars. 215. Bothe, Walther Wilhelm Georg Franz: $\begin{gathered}1891 \mathrm{AD} \\ \rightarrow\end{gathered}$ Made the coincidence counter which is an improved particle detector. 216.

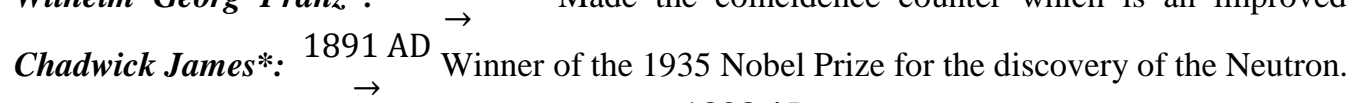

universe is expanding. 218. Louis de Broglie*: $\underset{\rightarrow}{1892} \mathrm{AD}$ Winner of the 1929 Nobel Prize. For the wave-particle duality

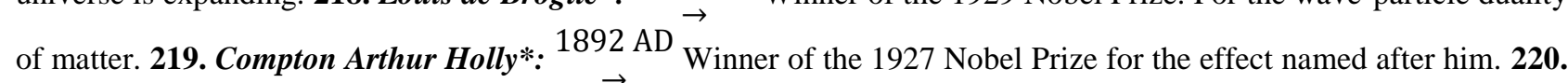
Thomson George Paget*: 1892 AD Winner of the 1937 Nobel Prize for experimentally proving the wave nature of electrons. 221. Wien Wlhelm: $\underset{1893}{\rightarrow} \mathrm{AD}$ Research on wavelength of maximum intensity of black body radiation which helped to measure the temperature of distant stars. 222. Philipp Lenard*: $\stackrel{1894 \text { AD }}{\rightarrow}$ Winner of Nobel Prize of 1905. Found that cathode rays can pass through thin metal foils and hence they cannot be electrically charged molecules. 223. Bose, Satyendra Nath: $\begin{gathered}1894 \text { AD } \\ \rightarrow\end{gathered}$ Research on Quantum Statistics. Collaborated with Albert Einstein and formulated Bose-Einstein Statistics. 224. Kapitza, Piotr Leonidovich*: ${ }^{1894}$ AD The 1978 Nobel Laureate. Outstanding discoveries in Low Temperature Physics. 225. Kramers Handrik Antony: 1894 AD Research on Raman scattering. Also worked on 'Renormalization'. 226. Lemaitre, Georges Edouard: $1894 \mathrm{AD}$ Gave the Big Bang description of the universe. 227. Tamm, Igor Yevgenyevich*: $1895 \mathrm{AD}$ Winner of the 1958 Nobel Prize for the discovery and interpretation of the Cherenkov effect. Explains Beta decay as a weak force between nucleons. 228. Germer, Lester Halbert*: $1896 \mathrm{AD}$ Winner of the 1937 Nobel Prize for his work on wave nature of electrons. 229. Milne, Edward Arthur: $\underset{1896 \overrightarrow{\mathrm{AD}}}{\rightarrow}$ Research on structure of stars. 230. Radioactivity: $1896 \mathrm{AD}$ Radioactivity discovered. 231. Blackett, Patrick Maynard*: 1897 AD Nobel Prize winner of 1948 for his research on Cosmic Rays and experiments with the cloud chamber. 232. J.J. Thomson: ${ }^{1897} \mathrm{AD}$ Asserted that cathode rays are nothing but electrons. 233.Cockcroft: $1897 \mathrm{AD}$ Research on artificial transmutation of elements known as splitting of atoms. 234. Juliot Curie*: 1897 AD Winner of Nobel Prize in Chemistry in 1935 for research on artificial radioactivity. 235. Atkinson Robert: $\begin{array}{r}1898 \mathrm{AD} \\ \rightarrow\end{array}$ Research on fusion inside stars. 236. Rabi, Isidor Isaac*. 1898 AD Winner of Nobel Prize of 1944. Measurement of magnetic moment of electron by resonance method. 237. Szilard, Leo: 1898 AD $\rightarrow$ Took part in the development of the nuclear bomb. 238. Zwicky, Fritz: $\underset{\rightarrow}{1898}$ AD Made many contributions to Astrophysics. Studied Supernova. Developed the idea of neutron stars. 239. Auger, Pierre: $1898 \mathrm{AD}$ Says that an atom with excess energy can emit an electron instead of electromagnetic radiation. This effect is named after him as Auger effect. 240. Joliet-Curie, Frederic $*$ : $\underset{\rightarrow}{\longrightarrow}$ Shared the Chemistry Nobel Prize of 1935 for their research on Artificial Radioactivity. 153. Max Planck*: 


\title{
International Advanced Research Journal in Science, Engineering and Technology
}

\author{
Vol. 5, Issue 10, October 2018
}

$\underset{\rightarrow}{1900 \text { AD }}$ Announces his theory of Quanta. 241. London, Fritz Wolfgang: 1900 AD A pioneer in Quantum Chemistry. Studied covalent bond in hydrogen molecule. Did research on superconductivity. 242. Pauli, Wolfgang*: 1900 AD Winner of the 1945 Nobel Prize for the principle named after him known as the Pauli Exclusion principle. The principle is applied in the study of white dwarfs and neutron stars. First to propose the existence of 'Neutrino'. 243. Uhlenbeck, George Eugene: $1900 \mathrm{AD}$ Introduced the concept of electron spin. 244. Fermi, Enrico*: ${ }^{1901 \mathrm{AD}}$ Nobel laureate of 1938. Coined the word, 'Neutrino'. Took part in the Manhattan project in the making of a nuclear bomb. Famous for 'Fermi Energy' in semiconductors. 245. Electric Typewriter: $\begin{gathered}1901 \mathrm{AD} \\ \rightarrow\end{gathered}$ First electric typewriter manufactured. 246. Heisenberg, Werner*: $1901 \mathrm{AD}$ Winner of the 1932 Nobel Prize. Famous for the principle named after him according to which one cannot determine both the position and velocity of a particle similarly at the same time. Developed Matrix Mechanics. 247. Lawrence, Ernest Orlando*: $1901 \mathrm{AD}$ Winner of the 1939 Nobel Prize for the invention of the Cyclotron. Developed neutron beams for the treatment of cancer. 248. Brattain, Walter Houser*: 1902 AD Winner of 1954 Nobel Prize for his research on semiconductors and transistor effect. 249. Goudsmit Samuel $\overrightarrow{\text { Abraham: }} 1902 \mathrm{AD}$ Research on electron spin. 250. Jordan (Ernst) Pascual: 1902 AD Development of Matrix Mechanics. A pioneer in Quantum Electrodynamics. 251. Wigner, Eugene Paul*. 1902 AD Winner of 1963 Nobel Prize. Worked on the law of conservation of parity and modern field theory.252. von Neumann, John: 1903 AD Worked on the theory of hidden variables. 253. Wright brothers: $1903 \mathrm{AD}$ The first powered flight. 254. Powell, Cecil Frank $*: \begin{aligned} & 1903 \text { AD } \\ & \rightarrow\end{aligned}$ Winner of the 1950 Nobel Prize for the photographic method of studying nuclear processes. 255. Walton, Earnest Thomas Sinton $*: 1903$ AD Winner of 1951 Nobel Prize for the development of the Atom smasher. 256.

Cerenko $v^{*}: \begin{gathered}1904 \mathrm{AD} \\ \rightarrow\end{gathered}$ Winner of Nobel Prize of 1958 for the discovery and interpretation of the Cerenkov effect. 150.Lorentz, Hendrik Antoon*: 1904 AD Develops the relativistic transformation equations. 257. Frisch Otto Robert: $\underset{\rightarrow}{1904}$ AD Did research on Nuclear Fission. 258. Gamow, George: $\stackrel{1904 \text { AD }}{\rightarrow}$ Worked on Big Bang theory and predicted the existence of background radiation. Research on DNA, the molecule of life. 259. Kronig, Ralph de Laer: 1904 AD Research on Electron Spin. 260. Oppenheimer, Robert: $\begin{aligned} & 1904 \text { AD } \\ & \rightarrow\end{aligned}$ A chief physicist in the Manhattan project and the first director of the Los Alamos Laboratories. 261. Anderson, Carl David*: 1905 AD $\rightarrow^{\rightarrow}$ Winner of the 1936 Nobel Prize for the discovery of Positron - the first proof of the existence of Antimatter. 185. Einstein Albert*: 1905 AD Publication of the Special Theory of Relativity. 262. Mott Nevill Francis*: $\begin{gathered}1905 \mathrm{AD} \\ \rightarrow\end{gathered}$ Winner of the Nobel Prize of 1977. Research on semiconductors and Quantum theory of atomic collisions. 263. Segre, Emilo*: ${ }^{1905 \text { AD }}$ Winner of the 1959 Nobel Prize for the discovery of Anti proton. Credited with the discovery of Plutonium. 264. Bethe, Hans Albrecht*: ${ }^{1906 A D}$ Winner of the 1967 Nobel Prize. Development of Quantum Physics. Did research on energy production in stars. 265. Coeppert,-Mayer, Marya $*$ 1906AD Winner of the 1963 Nobel Prize for developing the Shell model of the nucleus. 266. Ruska, Ernst August*: $\underset{\rightarrow}{1906 \mathrm{AD}}$ Winner of the 1986 Nobel Prize for research on electron optics and the development of the first electron microscope. 267. Tomonaga Sin-itiro*: 1906 AD $\rightarrow$ Winner of 1965 Nobel Prize for the research on Quantum Electrodynamics. 268. Jensen Hans Daniel*: $\underset{\rightarrow}{1907 \mathrm{AD}}$ Winner of the Nobel Prize of 1963 for the research on structure of the nucleus. 269. London Heinz: $\stackrel{\text { 1907AD }}{\rightarrow}$ Research on super fluidity and techniques of separating isotopes. 185. Einstein Albert $*$ : ${ }_{\rightarrow} 907$ AD Einstein's principle of equivalence stating that gravity and acceleration are equivalkent. 270. Color Photography: 1907 AD Color Photography invented. 271. Peierls, 


\title{
International Advanced Research Journal in Science, Engineering and Technology
}

\author{
Vol. 5, Issue 10, October 2018
}

Rudolf Ernst: 1907 AD Research on Quantum Theory. Suggested a 'Super Bomb'. Leader of the British group in the Manhattan Project. 272. Yukawa Hideki*: 1907 AD The Nobel laureate of 1949 for the discovery of Meson. 273. Bardeen John $* *: \begin{aligned} & 1908 \text { AD } \\ & \rightarrow\end{aligned}$ Twice the winner of Nobel Prize. One in 1956 and the other in 1972 for his research on semiconductors and Transistor effect. 274. Heike Onnes*: 1908 AD Nobel Prize winner of 1913 for his research on low temperature Physics and production of liquid helium. 275. Frank, llya Mikhallovitch*: 1908 AD $\rightarrow$ Winner of the 1958 Nobel Prize for his research on Cerenkov effect. 276. Landau, Lev Davidovich*: ${ }_{\rightarrow}^{\rightarrow}$ Winner of 1962 Nobel Prize for his research on super fluidity and theoretical studies on liquid helium. 277. Teller, Edward: ${ }^{1908 \text { AD }} \rightarrow$ Known as the father of the hydrogen bomb. Took part in the Manhattan project. 278. Casimir, Hendrik Brugt Gerhardt: 1909 AD Research on theory of superconductivity. Discovery of a new Quantum force known as Casimir effect. 279. Ulam, Stanislaw Marcin: $\begin{array}{r}1909 \mathrm{AD} \\ \rightarrow\end{array}$ Designed the first hydrogen bomb. 280.Chandrasekhar Subramanyan*: $1910 \mathrm{AD}$ Winner of the 1983 Nobel Prize for his research on white dwarfs, black holes. Famous for the Chandrasekhar limit. 281. Shockley, William Bradford $*: \underset{\rightarrow}{1910}$ AD Nobel prize winner of 1956 for the invention of the Transistor. 282. Alvarez Luis Walter*: $\stackrel{1911 \text { AD }}{\rightarrow}$ Winner of 1968 Nobel Prize for the development of Hydrogen Bubble Chamber technique. 175. Rutherford Earnest*: $1911 \mathrm{AD}$ Announces the nuclear model of the atom. 151. Onnes, Heike Kamerligh $*: \begin{aligned} & 1911 \mathrm{AD} \\ & \rightarrow\end{aligned}$ Discovers Superconductivity. 283. Fowler, William Alfred $*$ : $\rightarrow$ W $\rightarrow$ Winner of the 1983 Nobel Prize for Nucleo synthesis, that is the production of elements in stars. 284. Wheeler, John Archibald: 1911 AD Worked on General Theory of Relativity in search of a unified field theory. 285. Wu, Chien Shiung: $191 \overrightarrow{1}$ AD Performed experiments that violate Parity'. 286. Victor Hess: 1912 AD Research on Cosmic rays. 287. The Titanic: $\begin{aligned} 1912 \mathrm{AD} \\ \rightarrow\end{aligned}$ Sinks. 288. Lamb, Wills Eugene, Jr*: 1913 AD Winner of 1955 Nobel Prize for his precise measurements in the hydrogen spectrum. Famous for the Lamb Shift in Quantum Electrodynamics. 289. Niels Bohr*:

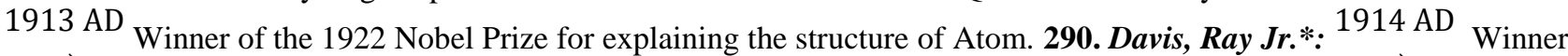
of $\overrightarrow{2002}$ Nobel prize. Devised and built the first experiment to measure the flux of neutrinos from the Sun. 291. Vesto Slipher: $1914 \mathrm{AD}$ Working at Lowell Observatory found Red Shift in their galaxies. 292. Hofstadter, Robert*: $\stackrel{1915 \mathrm{AD}}{\rightarrow}$ Winner of the 1961 Nobel Prize for his pioneering studies on electron scattering in atomic nuclei. 185. Einstein Albert*: $\begin{gathered}1915 \text { AD } \\ \rightarrow\end{gathered}$ Albert Einstein's General Theory of Relativity is presented to the Prussian Academy of Sciences. 293. Hoyle, Sir Fred: 1915 AD Propounder of the Steady state theory of the universe.294. Shull, Clifford Glenwood $*$ : 1915 AD Winner of the 1994 Nobel Prize for his work on Neutron scattering and structure of matter. 295. Townes, Charles Hard $*: \begin{aligned} & 1915 \text { AD } \\ & \rightarrow\end{aligned}$ Winner of 1964 Nobel Prize for the development of the Maser. 296. Dicke, Robert Henry: $1916 \mathrm{AD}$ Investigations of Cosmic Background Radiation. 297. Prokhorov, Alexander Mikhailovich*: 1916 AD $\vec{\rightarrow}$ Winner of 1964 Nobel Prize for the development of the Maser. 298. Bohm, David Joseph: 1917 AD Contribution to Quantum Mechanics. Worked on the Manhattan Project. 299. Rainwater (Leo) James*: $1917 \mathrm{AD}$ Research on the structure of nucleus and pion scattering. 300. Feynman, Richard Phillips $*$ 1918 AD Winner of the 1965 Nobel Prize for the development of Quantum Electrodynamics. Famous for Feynman diagrams in particle Physics. 301. Frederik Reines*: 1918 AD Winner of the 1995 Nobel Prize for the detection of the Neutrino. 302. Julian

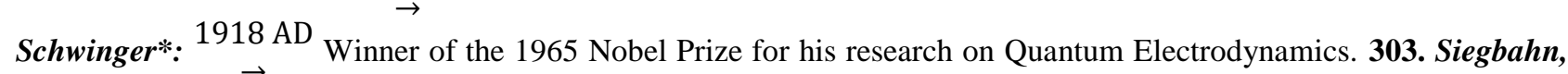
Kai Manne*: $\underset{\rightarrow}{1918}$ AD Winner of the 1981 Nobel Prize for his research on high resolution electron spectroscopy. 304. 


\section{International Advanced Research Journal in Science, Engineering and Technology}

Vol. 5, Issue 10, October 2018

Bondi, Sir Hermann: $1919 \mathrm{AD}$ One of the original proponents of the Steady State Universe. 305. Cowen, Clyde Lorrain Jr.: $\underset{\rightarrow}{1919}$ AD First detected Neutrinos in 1956. . 185. Einstein Albert*: $\stackrel{1919 \text { AD }}{\rightarrow}$ Einstein's General Theory of Relativity verified during a Solar Eclipse. 306. Chamdiscovery of the berlain Owen*: $1920 \mathrm{AD}$ Winner of the 1959 Nobel Prize for the discovery of the Anti-Proton. 307. Radio broadcasting: $\begin{gathered}1920 \mathrm{AD} \\ \rightarrow\end{gathered}$ Started. 308. Pippard Alfred Brian: $\begin{gathered}1920 \mathrm{AD} \\ \rightarrow\end{gathered}$ Used microwave radiation to study the behavior of the surface of superconductos. The concept of 'Coherence' introduced for the first time. 309. Sakharov, Andrei Dimitrievich*: $\begin{gathered}1920 \text { AD } \\ \rightarrow\end{gathered}$ Winner of the Nobel Peace prize for opposing the manufacture of nuclear weapons. Initially he was involved in the manufacture of hydrogen bombs for the Soviet union. 310. Basov, Nicolay Gennadiyevich $*$ : 1922 AD Winner of the 1964 Nobel prize. For the development of Masers and Lasers. First to make semiconductor lasers. 311. Leon, Max Lederman*: 1922 AD Winner of the 1988 Nobel prize for the neutrino beam method and the demonstration of the doublet structure of the leptons through the discovery of the muon neutrino. 312. Yang, Chen Ning*: $\stackrel{1922 \mathrm{AD}}{\rightarrow}$ Winner of the 1957 Nobel prize for the law of parity which helped many problems in particle Physics. 313. Anderson, Phillip Warren*: ${ }^{1923 \text { AD }}$ Winner of the 1977 Nobel prize for the fundamental theoretical investigations of the electronic structure of magnetic and disordered systems. 314. Dyson, Freeman John: 1923 AD Research on Quantum Electrodynamics. 315. Fitch, Val Lodgson*: $\underset{\rightarrow}{1923 \text { AD }}$ Winner of the 1980 Nobel prize for the discovery of violations of fundamental symmetry principles in the decay of neutral K-Mesons. 316. Charpak Georges*: 1924 AD Winner of the 1992 Nobel prize for the multiwire proportional chamber. 317. Esaki, Leo*: $1925 \mathrm{AD}$ Winner of the 1973 Nobel Prize for the discovery of tunneling phenomena in semiconductors. 318. Van der Meer, Simon $*$ : 1925 AD $\rightarrow$ Winner of the 1984 Nobel Prize for the development of the technique known as Stochastic cooling at the CERN. 319. Nee'man Yuval: 1925 AD Developed a theoretical basis for the Quark model. 320. Glaser, Donald Arthur: $1926 \mathrm{AD}$ Invented the Bubble chamber. 321. Kendral, Henry Way*: ${ }_{\rightarrow}^{1926 \text { AD }}$ Winner of the 1990 Nobel Prize for the introduction of the Quark model in particle Physics. 322. Lee, Tsung Dao*: 1926 AD Winner of the 1957 Nobel Prize for investigation of law of parity in particle Physics. 323. Mottelson. Ben Roy*: $\overrightarrow{1926}$ AD Winner of the 1975 Nobel Prize for the theory of the structure of atomic nuclei. 206.Schrodinger, Erwin $* \underset{\rightarrow}{1926}$ AD Publishes the development of wave mechanics. 324. Nishijima, Kazuhiko: $\begin{aligned} 1926 \mathrm{AD} \\ \rightarrow\end{aligned}$ Predicts that a second neutrino accompanies muon. 325. Robert Goddard: $\begin{gathered}1926 \mathrm{AD} \\ \rightarrow\end{gathered}$ Develops the liquid-fuelled rocket. 326. Salam, Abdus*: $\underset{\rightarrow}{1926 \mathrm{AD}}$ Winner of the 1979 Nobel Prize for the development of theory of electro-weak interaction. 327. Maiman, Theodore Herald: 1927 AD Builds the first Laser in 1960. 328. Muller, (Karl) Alex*: ${ }_{\rightarrow}^{1927}$ AD Winner of the 1987 Nobel Prize for the discovery of high temperature superconductivity. 200. Bohr, Niels Hendrik David*: 1927 AD Presents the Copenhagen interpretation of Quantum

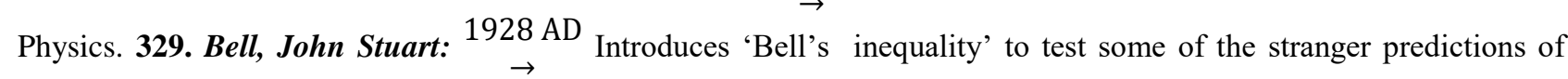
Quantum Theory. 330. Friedman, Jerome Isaac $*$ $1928 \mathrm{AD}$ Winner of the 1990 Nobel prize for the research on inelastic scattering of electrons on protons which was essential for the Quark model of particle Physics. 258. Gamow, George: $1928 \mathrm{AD}$ The tunnel effect observed in Alpha decay by George Gamow. 209. Raman Chandrasekhara Venkata*: $\underset{\rightarrow}{1928}$ AD Raman effect observed. 331. Gell-Mann, Murray*: $\stackrel{1929 \text { AD }}{\rightarrow}$ Winner of the 1969 Nobel Prize for classification of elementary particles. Introduced the idea of Quarks in particle Physics. 332. Glaever, Ivar*: 1929 AD Winner of the 1973 Nobel Prize in Physics for research on tunneling phenomena in semiconductors and 


\section{International Advanced Research Journal in Science, Engineering and Technology}

Vol. 5, Issue 10, October 2018

superconductors. 237. Szilard, Leo: $\stackrel{1929 \mathrm{AD}}{\rightarrow}$ Solves the puzzle of Maxwell's Demon. 333. Higgs, Peter*: ${ }^{1929} \mathrm{AD}$ Winner of the 2013 Nobel Prize for the discovery of the Higgs Boson, the God's particle. 334. Mossbauer, Rudolf Ludwig*: $1929 \mathrm{AD}$ Winner of the 1961 Nobel Prize for the discovery of transitions of electrons between energy levels and this effect is known by his name. 335. Taylor, Edward Richard*: 1929 AD Winner of the 1990 Nobel Prize for his contribution to the experimental work which confirmed the existence of Quarks. 336. Cooper, Leon Niels*: $1930 \mathrm{AD}$ Winner of the 1972 Nobel Prize for the development of super conductivity known as the BCS theory.337. Everet, Huge: ${ }^{1930 \mathrm{AD}}$ Developed the many worlds interpretation of Quantum Mechanics while being a graduate student at Princeton. 241. London, Fritz Wolfgang: $\stackrel{1930 \mathrm{AD}}{\rightarrow}$ Calculates the strength of Van der Walls forces. 338. Cronin, JamesWatson*: $\stackrel{1931 \mathrm{AD}}{\rightarrow}$ Winner of the 1980 Nobel Prize for the discovery of violations of fundamental dsymmetry principles in the decay of neutral K-mesons. 280.Chandrasekhar Subramanyan*: $\rightarrow$ AD Arrives at the Chandrasekhar Limit in Astronomy. 339. Penrose, Roger: 1931 AD Made major contributions in the theory of black holes. 340. Richter, Burton*: $1931 \mathrm{AD}$ Winner of the 1976 Nobel Prize for the discovery of j/psi particle. 341.

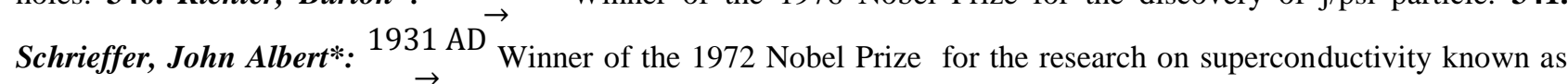
the BCS theory. 342. Glashow, Sheldon Lee*: ${ }^{1932}$ AD Winner of the 1979 Nobel Prize for the development of the electroweak theory paving the way for the standard model of particle Physics. 343. Schwartz, Melvin*: $1932 \mathrm{AD}$ Winner of the 1988 Nobel Prize for the discovery of muon neutrino. 344. Penzias, Arno Allan: $\begin{aligned} & 1933 \text { AD } \\ & \rightarrow\end{aligned}$ Accidently discovered cosmic background radiation. 345. Weinberg, Steven*: 1933 AD Winner of the 1979 Nobel Prize for research on electro weak interactions that led to the prediction of neutral currents. 346. Bjorken, James David: 1934 AD Developed parton model of nucleons which led to the idea of Quarks as the fundamental building blocks of matter. 347. Cramer, Johjn: $\stackrel{1934 \mathrm{AD}}{\rightarrow}$ Developed the transactional interpretation of Quantum Mechanics. 348. Kerr, Roy Patrick: $\overrightarrow{1934 \mathrm{AD}}$ Deep understanding of black holes. Also developed the Kerr solutions for the equations of General Theory of Relativity. 349. Carlo Rubbia*: ${ }^{1934 \text { AD }}$ Winner of the 1984 Nobel Prize for discovery of W and Z particles. 350. Peebles, (Phillip) James Edwin: $\underset{\rightarrow}{1935}$ AD Study of the Physics of the Big Bang and background radiation. 351. Richter: ${ }^{1935 \mathrm{AD}}$ Invents the earthquake scale. 352. Ting, Samuel Chao Chung*: ${ }^{1936 \mathrm{AD}}$ Winner of the 1976 Nobel Prize for the discovery of a heavy elementary particle, 1/psi. 353. Wilson, Robert Woodrow: $1936 \mathrm{AD}$ Accidental discovery of the Cosmic Background Radiation. 354. Zweig, George: ${ }^{1937}$ AD An independent inventor of Quark. 355. Josephson, Brian David $*:{ }^{1940} \mathrm{AD}$ Winner of the 1973 Nobel Prize for the invention of Josephson junction. 356. Schwartz, John: 1941 AD $\vec{\rightarrow}$ Development of the 'String' Theory in Particle Physics. 357. Nucleon: $\underset{\rightarrow}{1941 \mathrm{AD}}$ First use of the term, 'Nucleon'. 358. The Controlled Nuclear Reaction: $\stackrel{1942 \mathrm{AD}}{\rightarrow}$ World's first controlled nuclear reaction in a reactor, Pile-1 in the Stagg Fields of the University of Chicago by Enrico Fermi and his team. 359. Bell, Burnell (Susan) Jocelyn: ${ }^{1943} \mathrm{AD}$ Discovered Pulsars in 1967. 360. Electronic Computer: $\stackrel{1943 \mathrm{AD}}{\rightarrow}$ Made first electronic Computer. 361. Klitzing, Klaus von $* \underset{\rightarrow}{1943 \mathrm{AD}}$ Winner of the 1985 Nobel Prize for the discovery of the quantized Hall Effect which has applications in Electronics. 362. Nuclear Bombs: $1945 \mathrm{AD}$ The bombings of Hiroshima and Nagasaki of Japan. 363. Willard Libby: $1946 \mathrm{AD}$ Carbon dating technique developed. 364. Binnig, Cerd Karl *: $\begin{aligned} & 1947 \text { AD } \\ & \rightarrow\end{aligned}$ Winner of the 1986 Nobel Prize for the design and development of the scanning tunneling microscope. 365. Supersonic Flight: $\stackrel{1947}{\rightarrow}$ AD Launched. 366. Guth, Alan Harvey: $\stackrel{1947 \mathrm{AD}}{\rightarrow}$ American physicist who 


\title{
International Advanced Research Journal in Science, Engineering and Technology
}

\author{
Vol. 5, Issue 10, October 2018
}

came up with the idea of inflation. 367. Linde, Andrei Dmitrivich: $1948 \mathrm{AD}$ Development of the theory of early universe. Research on Fermions in the context of gauge theories. 368. Ralph, Alpher and Robert Herman: 1948 AD extend the alpha, beta, gamma theory to predict that the universe today must be filled with background radiation at temperature of 5 K. 369. Atomic Clock: 1948 AD The first atomic clock developed using ammonia gas molecules. 370. Bednorz. George*: 1950 AD Winner of the 1987 Nobel Prize for the discovery of high temperature superconductivity. 371. Television Broadcast: $\begin{array}{r}1950 \mathrm{AD} \\ \rightarrow\end{array}$ Television broadcasting takes off. . 295. Townes, Charles Hard $*$ 1951 AD Builds the first Maser at Columbia university. . 305. Cowen, Clyde Lorrain Jr.: 1956 AD Monitor the flood of neutrinos emitted by a nuclear reactor at Savannah River in the United States. 300. Feynman, Richard Phillips $*$ 1962 AD Develops the concept of Quantum Gravity.

The above list contains Nobel laureates in Physics up to the year 1987

\section{PART II}

3.1 List of Nobel Laureates in Physics from 1988 to date

Nobel laureates of 1988 and onwards till date being of recent origin, they are given below. If there is any repetition, the serial number will be maintained.

372. Jack, Steinberg*: ${ }^{1921 \text { AD }} \rightarrow$ Winner of 1988 Nobel Prize for the neutrino beam method of the demonstration of the doublet structure of the leptons through the discovery of the muon neutrino.373. Norman Foster Ramsey*: 1915 AD Winner of the 1989 Nobel Prize for the invention of the separate oscillatory fields method and its use in the hydrogen maser and other atomic clocks. [374. Hans Georg Dehmelt*: $1922 \mathrm{AD}$ and 375. Wolfgang Paul*: ${ }^{1913 \mathrm{AD}}$ ] Winners of the 1989 Nobel Prize for the ion trap technique. [ 335. Taylor, Edward Richard*: 1929 AD, 376. Henry Way Kendal*: and 377.Jerome I Friedman*: ] Winners of the 1990 Nobel Prize for their pioneering work concerning deep inelastic scattering of electrons on protons and bound neutrons, which have been essential importance for the development on the Quark model of particle Physics. 378. Piere, Gilles de Gennes*: 1932 AD Winner of the 1991 Nobel Prize for discovering that methods developed for the study of order phenomena in simple materials such as liquid crystals and polymers. 316. Charpak Georges*: $1924 \mathrm{AD}$ Winner of 1992 Nobel Prize for the invention and development of particle detectors in particular the multiwire proportional chamber.[379. Joseph Hooton Taylor Jr.*: $\underset{\rightarrow}{1941 \mathrm{AD}}$ and 380. Russel Alan Hulse ${ }^{*} \stackrel{1950 \mathrm{AD}}{\rightarrow}$ ] Winners of the 1993 Nobel Prize for their discovery of a new type of Pulsar leading to the study of gravitation. .294. Shull, Clifford Glenwood*: 1915 AD $\rightarrow$ Winner of the 1994 Nobel Prize for the neutron diffraction technique. and 380. Bertran Brokehouse $* \underset{\rightarrow}{1918 \text { AD }}$ Winner of the 1994 Nobel Prize for the development of Neutron Spectroscopy and neutron scattering. 301. Frederik Reines*: $1918 \mathrm{AD}$ Winner of the 1995 Nobel Prize for the detection of the neutrino and development of Lepton Physics. 381. Martin Lewis Pere*: $\begin{gathered}1927 \text { AD } \\ \rightarrow\end{gathered}$ Winner of the 1995 Nobel Prize for the discovery of Tau Lepton. [382. David, M Lee*: $\underset{\rightarrow}{1931 \mathrm{AD}}$, 383. Robert, C Richardson $*: \begin{gathered}1937 \mathrm{AD} \\ \rightarrow\end{gathered}$ and 384. Douglas, D Osheroff*: ${ }_{\rightarrow}^{1945 \mathrm{AD}}$ ] Winners of the 1996 Nobel Prize for their discovery of Superfluidity in Helium-3.

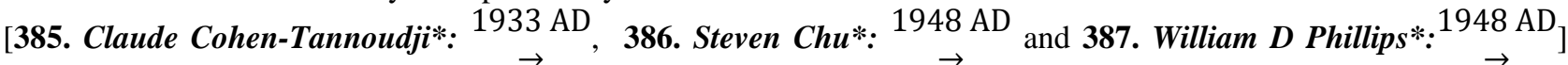
Winners of the 1997 Nobel Prize for their development of methods to $\overrightarrow{c o o l}$ and trap atoms using Laser. [388. Daniel $\boldsymbol{C}$ Tsui*: $\begin{gathered}1939 \mathrm{AD} \\ \rightarrow\end{gathered}$, 389. Horst. L. Sormer*: $\begin{gathered}1949 \mathrm{AD} \\ \rightarrow\end{gathered}$ and Robert, B. Laughlin*: $1950 \mathrm{AD}$ ] Winners of the Nobel Prize of 1998 for their discovery of a new form of Quantum fluid with fractionally charged excitations. [390. Martinus J.G. Veltman*: $\underset{\rightarrow}{1931 \mathrm{AD}}$ and 391. Jerardus 't Hooft $* \underset{\rightarrow}{1946} \mathrm{AD}_{\text {] }}$ winners of the 1999 Nobel Prize for elucidating the Quantum structure of electro weal interactions in Physics. [392. Herbert Kroemer*: ${ }^{1928 \text { AD }}$ and 393. Zhores I 


\title{
International Advanced Research Journal in Science, Engineering and Technology
}

\author{
Vol. 5, Issue 10, October 2018
}

Alferov*: $\left.\begin{array}{c}1930 \mathrm{AD} \\ \rightarrow\end{array}\right]$ Winners of the 2000 Nobel Prize for developing semiconductor heterostructures used in highspeed-and opto-electronics. [394. Carl E Wieman*: $\underset{\rightarrow}{1951 \mathrm{AD}}$, 395. Wolfgang Ketterle*. ${ }^{1957}$ AD and 396. Eric A

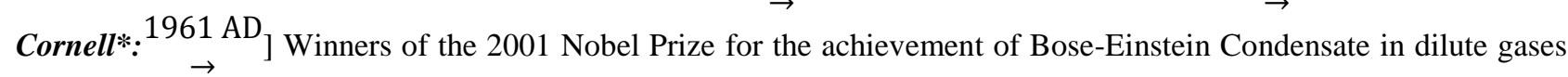
of alkali atoms, and for early fundamental studies of the properties of the condensates. .[ 290. Davis, Ray Jr.*: 1914 AD and 397. Masatoshi Koshiba*: 1926 AD ] Winners of the 2002 Nobel Prize for pioneering contributions to Astrophysics in particular for the detection of cosmic neutrinos. 398. Riccardo Giacconi $*$ : $1931 \mathrm{AD}$ Winner of the 2002 Nobel Prize for pioneering contributions to Astrophysics which led to the discovery of $\overrightarrow{c o s m i c} \mathrm{X}$-ray sourcs. [399. Vitaly L Ginzburg*: ${ }^{1916 \mathrm{AD}}$, 400. Alexi A Abrikosov*: $1928 \mathrm{AD}$ and 401. Anthony J Leggett*: ${ }^{\rightarrow} \rightarrow 38 \mathrm{AD}$ ] Winners of the 2003 Nobel Prize for pioneering contribution to the theory of superconductors and super fluids. 402.David J Gross*: ${ }^{1941 \mathrm{AD}}$, 403. H David Politzer: $\stackrel{1949 \mathrm{AD}}{\rightarrow}$ and 404. Frank Wilezek: ${ }^{1951 \mathrm{AD}}$ Winners of the 2004 Nobel Prize for the discovery of asymptotic freedom in the theory of strong interactions. 405. Roy J Glauber*: $1925 \mathrm{AD}$
$\rightarrow$ Winner of the 2005 Nobel Prize for his contribution to the Quantum Theory of Optical Coherence. [406. John L. Hall $*: \underset{\text { 1934AD }}{\rightarrow}$ and 407. Theodore. Hansch $* \underset{\rightarrow}{1941 \mathrm{AD}}$ ] Winners of the 2005 Nobel Prize for their contributions to the development of laser-based precision spectroscopy including the optical frequency comb technique.[ 408. George F. Smoot: $\stackrel{\text { 1945AD }}{\rightarrow}$ and 409. John C. Mather*: ${ }^{1946 \mathrm{AD}}$ ] Winners of the 2006 Nobel Prize for their discovery of the blackbody form and anisotropy of the cosmic microwave background radiation. [410. Albert Fert*: 1938 AD and 411. Peter Grunberg*: $1939 \mathrm{AD}_{]}$Winners of the 2007 Nobel Prize for discovery of "Giant Magnetoresistance". 412. Yoichiro Nambu $* \stackrel{192 \overrightarrow{1 A D}}{\rightarrow}$ Winner of the 2008 Nobel Prize for the discovery of the mechanism of spontaneous broken symmetry in sub-atomic Physics. [413. Toshihide Maskawa*: $1940 \mathrm{AD}_{\rightarrow}$ and 414. Makoto Kobayashi*: ${ }^{1944 \mathrm{AD}} \rightarrow$ Winners of the 2008 Nobel Prize for the discovery of the origin of the broken symmetry which predicts the existence of at least three families of quarks in nature. [415. Willard S. Boyle $* \underset{\rightarrow}{\text { 1924AD }}$ and 416. George E. Smith $*$. $^{\rightarrow}$ ] Winners of the 2009 Nobel Prize for the invention of an imaging semiconductor circuit - the CCD Sensor. 417. Charles Kuen Kao $*:{ }^{1933 \mathrm{AD}}$ Winner of the 2009 Nobel Prize for groundbreaking achievements concerning the transmission of light in fibers for optical communication. [418. Andre Geim $*$ 1958AD and 419. Konstantin Novoselov*: 1974AD $_{\rightarrow}$ ] Winners of the 2010 Nobel Prize for groundbreaking experiments regarding the two-dimensional material grapheme. [420. Saul I of the 2011 Nobel Prize for the discovery of the accelerating expansion of the universe through

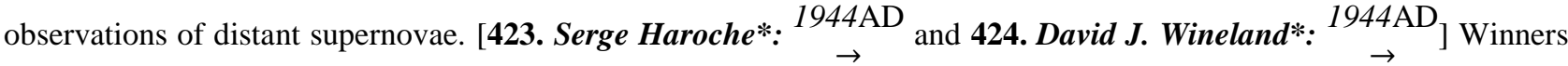
of the 2012 Nobel Prize for groundbreaking experimental methods that enable measuring and manipulation of individual Quantum systems. . [333. Higgs, Peter $* \underset{\rightarrow}{1929 \mathrm{AD}}$ and 425. Francois Englert*: ${ }^{1932 \mathrm{AD}}$ ] Winners of the 2013 Nobel Prize for the theoretical discovery of a mechanism that contributes to our understanding of the origin of mass of sub-atomic particles, and which recently was confirmed through the discovery of the predicted fundamental particle, by the ATLAS and CMS experiments at CERN's Large Hadron Collider. [426. Isamu Akasaki*: 1929AD, 427. Shuji Nakamura*: $\stackrel{1954 \mathrm{AD}}{\rightarrow}$ and 428. Hiroshi Amano*: $\stackrel{1960 \mathrm{AD}}{\rightarrow}$ ] Winners of the 2014 Nobel Prize for the invenwtion of efficient blue light-emitting diodes which has enabled bright and energy-saving white light sources. [429. Arthur B. Mc Donald $*: \begin{aligned} & \text { 1943AD } \\ & \rightarrow\end{aligned}$ and 430. Takaki Kajita $* \stackrel{1959 \mathrm{AD}}{\rightarrow}$ ] Winners of 2015 Nobel Prize for the discovery of Neutrino Oscillations which show that neutrinos have mass. [431. David J. Thouless $*$ 1934AD $\underset{\rightarrow}{\rightarrow}$ 432. F. Duncan M. Haldane $* \underset{\rightarrow}{1951 \mathrm{AD}}$ and 433. J. Michael Kosterlitz: $\underset{\rightarrow}{1943 \mathrm{AD}_{1}}$ ] Winners of the 2016 Nobel Prize for theoretical discoveries of topological phase transitions and topological phases of matter. [434. Reiner Weiss $*$ 1932AD $\rightarrow 435$. Barry C. Barish $*: \underset{\rightarrow}{1936 \mathrm{AD}}$ and 436. Kip S. Thorne*: $\underset{\rightarrow}{1940 \mathrm{AD}_{1}}$ ] Winners of the 2017 Nobel Prize for decisive contributions to the LIGO Detector and the observation of gravitational waves. 437. Arthur Ashkin $*$ 1922AD $\rightarrow$ Winner 


\section{International Advanced Research Journal in Science, Engineering and Technology}

Vol. 5, Issue 10, October 2018

of the 2018 Nobel Prize for the optical tweezers and their applications to Biological systems. [438. Gerard Mourou*: 1944AD and 439. Donna Strickland $*{ }^{1959 \mathrm{AD}}$ ] Winners of the 2018 Nobel Prize for their method of generating high intensity ultra-short optical pulses.

\section{PART III}

\subsection{Number of Physicists in the world given as per alphabetical order}

$\begin{array}{lccccccccccccc}\text { Alphabet } & \text { A } & \text { B } & \text { C } & \text { D } & \text { E } & \text { F } & \text { G } & \text { H } & \text { I } & \text { J } & \text { K } & \text { L } & \text { M } \\ \text { Number } & 47 & 83 & 50 & 39 & 26 & 47 & 59 & 61 & 10 & 21 & 52 & 55 & 56 \\ \text { Alphabet } & \text { N } & \text { O } & \text { P } & \text { Q } & \text { R } & \text { S } & \text { T } & \text { U } & \text { V } & \text { W } & \text { X } & \text { Y } & \text { Z } \\ \text { Number } & 20 & 15 & 50 & 01 & 51 & 96 & 41 & 04 & 17 & 50 & 01 & 07 & 18\end{array}$

Grand Total: 977

4.2 The Nobel Prize in Physics has been awarded 112 times to 210 Nobel Laureates between 1901 and 2018. John Bardeen is the only Nobel Laureate who has been awarded the Nobel Prize in Physics twice, in 1956 and 1972. This means that a total of 209 individuals have received the Nobel Prize in Physics.

From the above it is seen that the development of Physics (as per collection done by me) has been due to 439 scientists and philosophers. The number is slightly less because of the fact that in the links of the chain I have included some of the events such as 'Founding of some universities', 'Nuclear Bombs', etc. Subtracting those items from the 439, the figure can be approximated to, say 400.. Fit all things into the European Periods as shown jn Table.

Table: The European Periods (Marginally and suitably modified by author)

\begin{tabular}{|l|l|c|c|}
\hline No. & \multicolumn{1}{|c|}{ Name of Period } & Year & No. of Scientists \\
\hline 1 & The Classical Greece & $625 \mathrm{BC}-384 \mathrm{BC}$ & 9 \\
\hline 2 & Macedonian Era & $384 \mathrm{BC}-300 \mathrm{BC}$ & 4 \\
\hline 3 & Hellenestic Greece & $300 \mathrm{BC}-95 \mathrm{BC}$ & 7 \\
\hline 4 & Late Roman Republic & $95 \mathrm{BC}-27 \mathrm{BC}$ & 0 \\
\hline 5 & Principate of the Roman Empire & $100 \mathrm{AD}-500 \mathrm{AD}$ & 3 \\
\hline 6 & Late Antiquity & $500 \mathrm{AD}-1000 \mathrm{AD}$ & 4 \\
7 & & $1001 \mathrm{AD}-1500 \mathrm{AD}$ & 13 \\
\hline 8 & & $1501 \mathrm{AD}-2000 \mathrm{AD}$ & 360 \\
\hline
\end{tabular}

We now try to plot a graph of the year ( $\mathrm{x}$ - axis) versus the number of scientists ( $\mathrm{y}$ - axis). The year being a duration, can be taken as the middle of the duration. Periods Before Christ will be shown with a negative sign as follows:

$\begin{array}{crrrrrrrr}\text { Period (x-axis): } & -510 & -340 & -195 & -55 & 300 & 750 & 1250 & 1750 \\ \begin{array}{c}\text { No. of Scientists: } \\ \begin{array}{c}\text { (y-axis) } \\ \text { (y-axis }\end{array}\end{array} & 9 & 4 & 7 & 0 & 3 & 4 & 13 & 360\end{array}$




\section{International Advanced Research Journal in Science, Engineering and Technology}

Vol. 5, Issue 10, October 2018

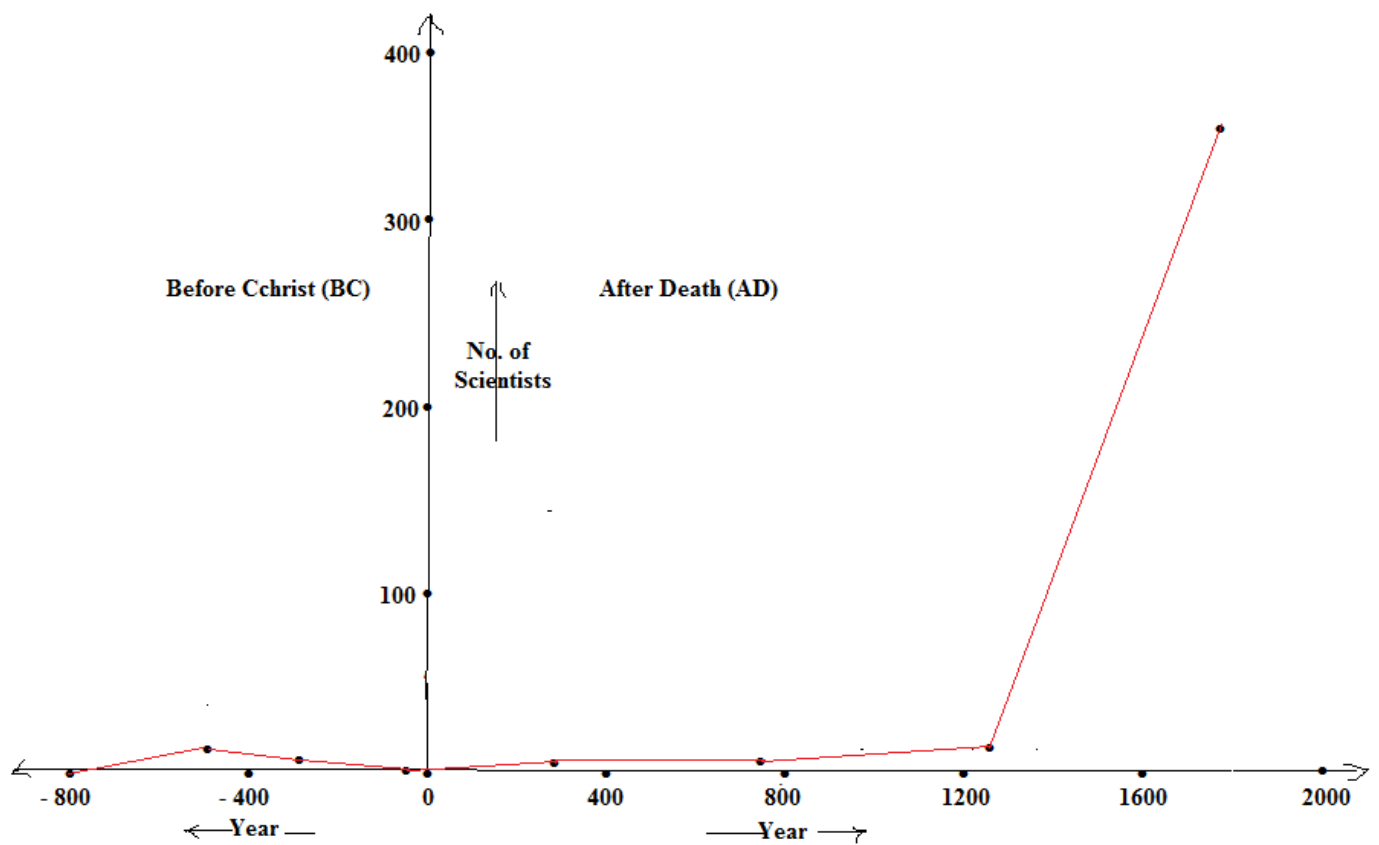

Fig. Graph showing the nature of development of Physics from past to the present

\section{CONCLUSION}

There are 400 scientists for the random choice done by us. There can be even more because Francis Bacon (1561-1626), a contemporary of Galileo have not been included. The omission is to maintain the brevity of the paper. Even 400 scientists, if we take one scientist per year, it is going to be 4 centuries of growth of Physics in which more than 200 , that is, more than half are Nobel laureates. This exposition is for the reader to understand and judge, as evident from the graph, the stagnation as the number of scientists shown as zero for the year $-55 \mathrm{BC}$, the transition thereafter up to year 1200 after which starts the renaissance which continues as on today. The renaissance and the scientific revolution started with Nicolaus Copernicus, later with "Isaac Newton, the Man", First of the Age of Reason and "Albert Einstein, as quoted in 'Hamlet' by Shakespeare, "A Man, Take him for all in all”.

\section{REFERENCES}

[1]. Physics 139- The Birth of Physics - The Ancient Greeks to the Renaissance

[2]. 'Q' is for 'Quantum',An Encyclopedia of Particle Physics By John Gribbin A Touch stone Book Published by Simon \& Schuster, New York,London \& Sydney Edition 2000.

[3]. Wikipedia - Edited on 18 Oct. 2018

\section{BIOGRAPHY}

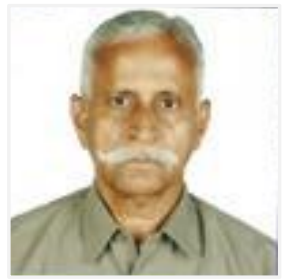

*Dr.(Prof.) V.C.A. Nair (b.15th Aug. 1939) is an Educational Physicist, Counselor, Research Guide and Consultant. He did his Masters in Physics from Mumbai University, India and Ph.D. from JJT University, Rajasthan also in India He is a Research Guide and distinguished alumni of JJT University. He is also a Chancellor designated Resource Person in the area of Physics in the University. He has to his credit over 4 decades of teaching Applied Physics in eminent Polytechnics in Mumbai and having taught nearly 16,000 students since 1965. He has published a number of research papers in Physics and Geophysics in International and UGC recognized Journals some of which can be seen in the net 'Google Search' when the name of the author or his e-mail is typed in that style. He is a Life Member of Indian Society for Technical Education which is an all India body. He had been to USA a number of times and visited eminent Universities such as Stanford, Harvard, MIT, 3 Universities of California at Berkeley, Los Angeles and also at Davis ,University of Princeton at New Jersey, University of Chicago and University of San Francisco. At present Dr. Nair is a Research Guide for Physics at Shri JJT University, Rajasthan333001, India . He is member of the Editorial Board of this Journal. His Ph.D. Thesis is in Geophysics and he is working on topics such as Tides, Clouds, Global Warming and Climate Change. - Editor.

*nairvca39@gmail.com. 